\title{
Education and transition to work among youth in Maharashtra
}

International Institute for Population Sciences (IIPS)

Follow this and additional works at: https://knowledgecommons.popcouncil.org/departments_sbsr-pgy

Part of the Demography, Population, and Ecology Commons, Family, Life Course, and Society Commons, Gender and Sexuality Commons, International Public Health Commons, Medicine and Health Commons, and the Sociology of Culture Commons How does access to this work benefit you? Let us know!

\section{Recommended Citation}

International Institute for Population Sciences (IIPS). 2008. "Education and transition to work among youth in Maharashtra," Youth in India: Situation and Needs Policy Brief no. 3. Mumbai: IIPS. 


\section{Education and transition to work among youth in Maharashtra}

\begin{abstract}
THE EXTENT TO WHICH INDIA WILL BE ABLE to successfully harness its demographic dividend depends significantly on the situation of its youth, notably on the levels of education and market-oriented skills they attain. In many states, youth have indeed made progress on these fronts. Youth in Maharashtra, for example, have made considerable strides in terms of educational attainment. Over $90 \%$ of youth had been to school and completed at least one year of schooling; and irrespective of sex and marital status, youth had attained a median of 8-9 years of schooling. Yet it is not clear that youth in Maharashtra are prepared for the challenges they will face in a globalised world. For example, are opportunities available to youth that enable them to complete secondary education, increasingly a prerequisite to participate in the labour market in the context of globalisation? ${ }^{\mathrm{a} b}$ Likewise, are opportunities available that enable youth to overcome skill mismatches through vocational skills training? Are youth in Maharashtra succeeding in finding productive employment and becoming integrated into the labour market? Are they transitioning into work roles at appropriate ages and with adequate skills? Also, given that achievement of the demographic dividend rests to a considerable extent on the expected rise in work participation of women, are opportunities available for young women to make the most of their productive potential?
\end{abstract}

Looking at the current educational and employment situation of youth in Maharashtra, this policy brief argues that significant investments in terms of appropriate policies and programmes are required to enable the state to harness its demographic dividend and its youth to participate in and benefit from global development.
The study

The Youth in India: Situation and Needs study is a sub-nationally representative study undertaken for the first time in India of key transitions experienced by young people in six states of India, including Maharashtra. The study included a representative survey of young people in both rural and urban settings. Respondents included unmarried women and men and married women aged 15-24 and, in view of the paucity of married men in these ages, married men aged 15-29.

In Maharashtra, the survey was conducted in 2006. A total of 7,570 married and unmarried young women and men were interviewed in the survey. These included 1,947 married young women, 2,541 unmarried young women, 1,065 married young men and 2,017 unmarried young men.

The majority of youth had not completed secondary education

Findings from the Youth Study indicate that while the vast majority of youth in Maharashtra had been to school, not many youth had completed secondary education; just $44 \%$ of young men and $39 \%$ of young women had completed 10 or more years of education. Indeed, even among those aged 18 and above, just about one in two young men (49\%) and over two in five young women (45\%) had completed secondary school.

Of note is the striking difference in the proportion of young people who had completed 10 or more years of education by economic status of young people's households. Differences by economic status were much wider than either gender differences or differences by rural-urban residence. For example, among young men, just $21 \%$ of

${ }^{a}$ United Nations. 2007. Goals and targets for monitoring the progress of youth in the global economy: Report of the Secretary-General. New York: United Nations.

b National Research Council and Institute of Medicine. 2005. Growing up Global: The Changing Transitions to Adulthood in Developing Countries. Washington, D.C.: The National Academies Press. 
those from households in the poorest wealth quintile had completed 10 or more years of schooling, compared to $76 \%$ of those from households in the wealthiest quintile. Among young women, the association was somewhat steeper: just $8 \%$ of those in the poorest wealth quintile compared to $73 \%$ of those in the wealthiest had completed 10 or more years of education. is not considered necessary, and respondent's own lack of interest were cited by over onethird of young men and women.

Many had not acquired vocational skills A number of vocational training programmes are available to youth through government, non-government and private organisations. However, findings indicate that just $22 \%$ of

Percentage of young people who had completed secondary school, according to household economic status

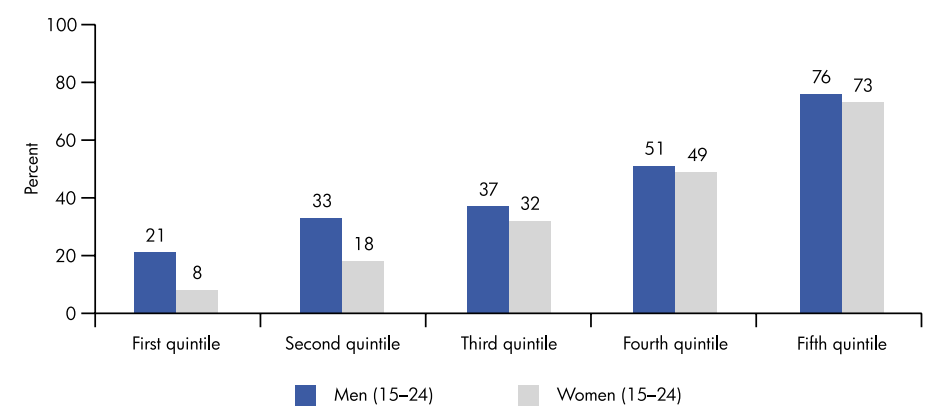

Reasons for school discontinuation among those who had discontinued their education after completing Class 7 and before completing Class 10

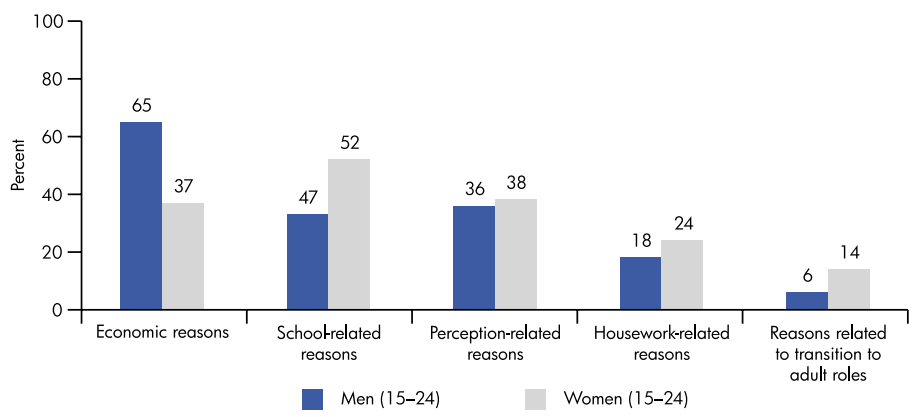

A number of factors inhibited secondary school completion. Leading among these were economic reasons, attitudes and perceptions of youth and their parents, and school-related reasons. For example, $65 \%$ and $37 \%$ of young men and women, respectively, who had discontinued schooling after completing Class 7 and before completing Class 10 reported that they had left school for economic reasons (work on the family farm or business, wage earning work, family poverty, i.e., the family could not afford to keep the respondent in school). School-related reasons, particularly academic failure and distance to school (among young women) also accounted for discontinuation among large percentages of young men and young women (47\% and 52\%, respectively). Perceptions that it is unsafe to send children to school and that education young men and $33 \%$ of young women had ever availed of the opportunity to attend a vocational training programme.

Moreover, findings show that the kind of training received varied by the sex of the respondent. Most young women who had received vocational training had typically acquired traditional skills. For example, among young women who had received any vocational skills training, 52\% reported training in tailoring compared to $32 \%$ in computer skills. Among young men, in comparison, leading training programmes reported were focused on computer skills (57\%), auto mechanics or electrical work (24\%) and driving (11\%).

Findings also show that large proportions 
of youth- $64 \%$ of young men and $71 \%$ of young women-were interested in acquiring vocational skills. While young men's preferences were focused on computer training, auto mechanics or electrical work and driving, the majority of young women continued to opt for relatively traditional vocational skills, indicating a considerable disconnect between young women's preferences and market needs.

Transition to work roles was not easy and successful for many

Work profiles of young people suggest that the majority of young men ( $62 \%$ of unmarried and $98 \%$ of married) and a substantial proportion of young women $(29 \%$ and $36 \%$, respectively) had engaged in paid or unpaid work at some point in the 12 months preceding the interview. Findings, however, highlight that the transition to work roles was fraught with many challenges.

\section{Sizeable numbers transitioned to work roles at young ages}

Despite global recognition that entry into the labour market at young ages competes with young people's schooling opportunities and experiences directly or indirectly, and compromises their productive potential and health, ${ }^{\text {b }}$ and despite significant policy and programme attention to prevent early entry into the labour market in India, ${ }^{c}$ findings indicate that sizeable proportions of young people had transitioned to work roles at young ages. Indeed, about one in five (19\%) young men and one in six (17\%) young women reported that they had initiated either paid or unpaid work before age 15 .

\section{Considerable proportions of young people were unemployed}

One in five young men and one in six young women reported unemployment. ${ }^{1}$ While unemployment rates were similar among both urban and rural young men, the rates among urban young women were twice as high as among their rural counterparts.

Notably, better educated youth were more likely to report unemployment than other youth, possibly because of the disconnect between youth skills and market needs. Young men and women who had completed Class 12 reported exceptionally high rates of unemployment (37-40\%).

\section{Many young women were neither in school nor} working

Findings suggest that large proportions of young men and young women were either in school or working at the time of the interview and a few were both working and studying. However, findings also show that the labour potential of young women was considerably under-utilised. For example, more than two in five young women were neither in school nor working, compared to just $5 \%$ of young men.

Unemployment rate among youth, according to selected characteristics

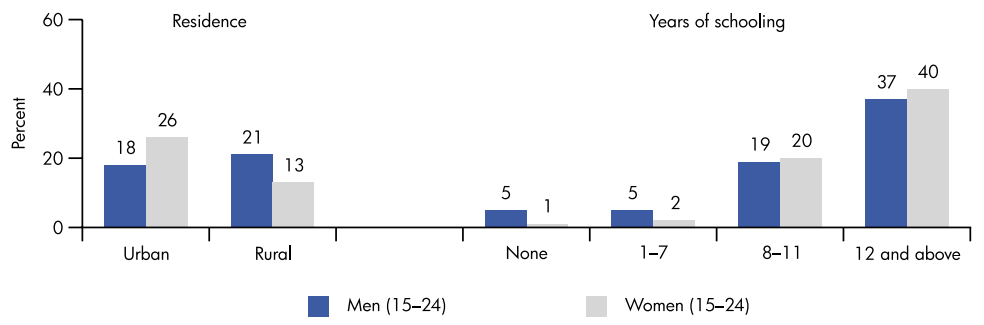

\footnotetext{
c Ministry of Labour and Employment. 1986. The Child Labour (Prohibition and Regulation) Act 1986. New Delhi: Government of India.

${ }^{1}$ To measure unemployment rates among respondents, the Youth Study assessed (a) whether youth had worked in the 12 months preceding the interview and if so, the number of months worked; and (b) whether youth were seeking work and if so, the number of months during which they had been searching for work. The unemployment rate is calculated as those seeking employment for the major part of the year preceding the interview as a fraction of those who were working or seeking work for the major part of the year, i.e., those in the labour force.
} 
